\title{
Secondary Electrospray Ionization (SESI) of Ambient Vapors for Explosive Detection at Concentrations Below Parts Per Trillion
}

\author{
Pablo Martínez-Lozano, a,b,* Juan Rus, ${ }^{\mathrm{b}}$ Gonzalo Fernández de la Mora, \\ Marta Hernández, ${ }^{\mathrm{c}}$ and Juan Fernández de la Mora ${ }^{\mathrm{a}}$ \\ ${ }^{a}$ Mechanical Engineering Department, Yale University, New Haven, CT, USA \\ b SEADM, Valladolid, Spain \\ ${ }^{\mathrm{c}}$ CARTIF, Valladolid, Spain
}

We determine the sensitivity of several commercial atmospheric pressure ionization mass spectrometers towards ambient vapors, ionized by contact with an electrospray of acidified or ammoniated solvent, a technique often referred to as secondary electrospray ionization (SESI). Although a record limit of detection of $0.2 \times 10^{-12}$ atmospheres $(0.2 \mathrm{ppt})$ is found for explosives such as PETN and $0.4 \mathrm{ppt}$ for TNT (without preconcentration), this still implies the need for some $10^{8}-10^{9}$ vapor molecules/s for positive identification of explosives. This extremely inefficient use of sample is partly due to low charging probability $\left(\sim 10^{-4}\right)$, finite ion transmission, and counting probability in the mass spectrometer (1/10 in quadrupoles), and a variable combination of duty cycle and background noise responsible typically for a $10^{3}$ factor loss of useful signal. (J Am Soc Mass Spectrom 2009, 20, 287-294) (C) 2009 Published by Elsevier Inc. on behalf of American Society for Mass Spectrometry

A number of mass spectrometry (MS) techniques have been used in the past for analysis of volatile species. The most natural and common combine gas chromatography (GC) with MS, most often (but not always) [1] charging and fragmenting the vapors by electron bombardment in the vacuum. Higher sensitivities have been achieved by instruments taking a larger gas sample flow rate $(\sim 1 \mathrm{~L} / \mathrm{min})$ directly into a reduced pressure region, where polar vapor species are charged by proton transfer reactions (PTR) in a glow discharge. This technique claims limits of detection in the range of $1 \mathrm{ppt}\left(10^{-12}\right.$ atmospheres) [2]. So-called Selected ion flow tube (SIFT) MS is a related technique, though it claims only ppb detection thresholds [3]. Various specialized instruments based also on PTR have reported limits of detection better than $1 \mathrm{ppt}$ in certain situations [4]. Atmospheric sampling glow discharge ionization (ASGDI) coupled with ion trap mass spectrometry has been studied by McLuckey and colleagues for explosive detection $[5,6]$. Negative ionization in their ASGDI is mostly due to free electron attachment to a neutral vapor molecule, $\mathrm{M}$, to produce $\mathrm{M}^{-}$. These and other journal articles as well as a variety of conference reports have concluded that the technique can detect $10 \mathrm{ppt}$ concentrations or $10 \mathrm{pg}$ of explosive [7]. A fourth approach to analyze ambient volatiles has

Address reprint requests to Dr. J. Fernández de la Mora, Mechanical Engineering Department, Yale University, P.O. Box 208286, 9 Hillhouse Avenue, New Haven, CT 06520-8286, USA. E-mail: juan.delamora@yale.edu * Current address: Institute for Biomedical Technologies-National Research Council, Via F.lli Cervi, 93, 20090 Segrate (MI), Italy. been based on atmospheric pressure ionization (API). It was first implemented for air monitoring applications through SCIEX's TAGA triple quadrupole in a van [8], which later evolved into the AROMIC explosives detector system (marketed as part of the CONDOR [9-15] contraband detection system by British Aerospace). These early developments are not readily accessible in the literature, but have been reviewed by Steinfeld and Wormhoudt [7]. With the advent of electrospray ionization (ESI) [16], API-MS shifted radically from a small effort in the area of volatile analysis to a vast enterprise in the analysis of involatile biological species, leading to drastic increases in API-MS sensitivity. Traditional LC-MS approaches $[17,18]$ as well as new ionization approaches such as DESI [19, 20] and DART [21] have been used for explosive analysis from the condensed phase. But the shift from gas to condensed phase analysis in the study of explosives has been maintained, with the notable exception of the early work by Fenn and his students, who had noted the remarkable ability of an electrospray cloud to produce ions from ambient vapors present in the laboratory at very small concentrations $[22,23]$. This peculiar way of ionizing vapors has been referred to as secondary ESI (SESI) in ion mobility spectrometry (IMS) studies by Hill and colleagues [24], who have also used SESI-IMS specifically for the study of explosives [25]. The number of new ES based techniques available for ionization of various substrates has grown substantially following the development of DESI [26], and this richness has given rise to some confusing interpretations. For instance, extractive 
Table 1. Variants used of each of the three components in the experimental system

\begin{tabular}{|c|c|c|}
\hline API-MS & Vapor generator & ES charger \\
\hline SCIEX API-365 & $\begin{array}{l}\text { Flask containing } \\
\text { crystals }\end{array}$ & Enclosed \\
\hline SCIEX API-365 & Injection of solution & $\begin{array}{l}\text { Enclosed and open } \\
\text { to lab }\end{array}$ \\
\hline SCIEX API- 5000 & Injection of solution & $\begin{array}{l}\text { Open to lab } \\
\text { atmosphere }\end{array}$ \\
\hline SCIEX Q-Star & Injection of solution & Enclosed \\
\hline
\end{tabular}

ESI (EESI) [27] was originally developed as a condensed phase ionizer, to analyze complex liquid matrices by atomizing them in the vicinity of an electrospray cloud. Zenobi and colleagues [28] have used this method to analyze breath, initially without reference to SESI, and under the assumption that their method was ionizing breath aerosol rather than vapors. It turns out, however, that an electrospray cloud is very effective in charging not only breath aerosol, but specially breath vapors directly [29], including those of urea and other substances presumed to be involatile. Hence, both gasphase (SESI) as well as condensed phase (EESI) charging might have taken place simultaneously in [28]. This richer situation is recognized in more recent work by Zenobi and colleagues [30,31], which now references prior SESI studies [23, 29], but confusingly refers to [29] as EESI. For greater clarity, we note that the explosives to be studied here are originally in the gas phase and not in solution or aerosol form (with one exception to be explicitly noted), and that they will be charged at atmospheric pressure by SESI, but could have alternatively been charged with a radioactive source or a corona.

The present study addresses the question of how sensitive to volatiles is SESI coupled to modern API-MS systems. Is this technique to be preferred over GC-MS or PTR-MS? And if so, is it good enough to meet real challenges of explosive detection? Surprisingly, following the early measurements reported, no quantitative information on the subject can be found in the literature. It seems as if the scientific community had reached a consensus against the viability of explosive detection in the gas phase, and shifted to condensed phase analyses. To re-evaluate the situation, we have examined the gas-phase sensitivity to explosives of several commercial API-MS instruments coupled to an electrospray charger.

\section{Experimental}

The experimental system includes three components: (1) a commercial API-MS, (2) a vapor generator, and (3) a charger. The diverse combinations of these three components used in our experiments are noted in Table 1. The API-365 is an old vintage ( $>12$ y) triple quadrupole MS. The API-5000 is SCIEX's most sensitive and modern triple quadrupole MS. The Q-Star is a quadrupole-TOF

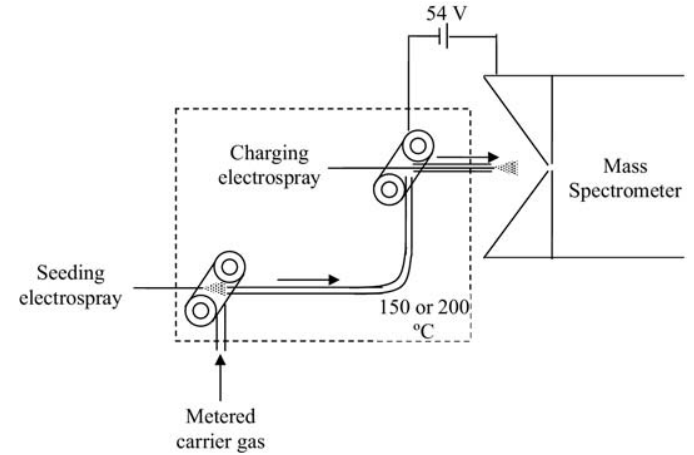

Figure 1. Schematic of the vapor-seeding system used (lower left) for addition of a known flow of sample solution through a capillary into a heated carrier gas, where the liquid is electrosprayed to ensure rapid sample evaporation. The figure (right) illustrates also the open charger configuration used with the API-5000.

instrument with an ion source almost identical to that of the API-365, though with improved ion optics and transmission, and high-resolution $\left(\sim 10^{4}\right)$ in the TOF stage. The charger used in all experiments is based on prior work [22-25], and has already been described [29]. A cloud of charged drops is electrosprayed from a capillary coaxially with the atmospheric pressure inlet orifice of the MS (Figure 1). Note the intermediate chamber between the mass spectrometer orifice leading to the vacuum and the chamber holding the ES. A flow of nitrogen exits towards the left through the larger hole on the apex of the conical piece shown. Hence, to reach the inlet orifice to the mass spectrometer, the ES ions must penetrate against this "curtain gas" propelled by an electric field. The region between the ES needle and the inlet orifice is bathed by the analyte vapor, providing a chance for the vapor molecules to be charged either directly from the drops, or indirectly from the ions produced by drop evaporation. We control the charging reagent (ammonia; acetic, formic, or nitric acid, etc.) by dissolving it into the electrospraying liquid (methanol/water 90/10 vol/vol). For most experiments with the API-365 and all Q-TOF experiments, the charging chamber sketched in Figure 1 was tightly closed with an additional plate forming the base of the cone shown. This plate incorporated two 1/4- in. (o.d.) tubes. The gas carrying the sample vapor enters through one of these tubes, circulates inside the chamber, and leaves continuously through the other tube. This enclosed system enabled analyzing vapors seeded in clean gases, probably reducing background interferences. The experiments with the API-5000 used the open configuration of Figure 1, with the charging region open to the atmosphere. This open scheme was previously tested on the API-365, demonstrating a similar response to that of the closed chamber.

Two different vapor-seeding systems were used. The first was just a glass flask with entry and outlet tubes 4 $\mathrm{mm}$ i.d. The substance to be seeded in the carrier gas circulating through the chamber was deposited on the 
internal walls of the flask in methanolic solution. Once the alcohol had evaporated, the sample remained attached to the wall in the form of small crystals. The method was eventually abandoned because particles as well as vapors were entrained by the gas, complicating the interpretation. The most interesting observation was that the ES cloud was able to ionize the explosive in vapor as well as aerosol form, a point previously demonstrated by Fenn and colleagues for peptide particles, and explained as due first to dissolution of the particles in the charged ES drops, and then to ionization by the same principles governing electrospray charging of solutes [23]. All subsequent work has proceeded with the alternative vapor seeding system sketched in Figure 1 , based on mixing into a fixed flow rate of gas a controlled liquid flow rate $\mathrm{Q}$ of alcohol containing a known concentration of explosive. The liquid flow rate $Q$ of alcohol was controlled accurately by forcing it through a capillary tube by a pressure difference $\Delta \mathrm{P}$ from a centrifuge vial (Figure 1, bottom left) into the other open end of the capillary, where it evaporated and mixed with the gas. Because the liquid flow is laminar, $\mathrm{Q}$ is given by Poiseuille's formula: $\mathrm{Q}=$ $\pi \mathrm{R}^{4} \Delta \mathrm{P} /(8 \mu \mathrm{L})$, where $\mathrm{L}$ is the length of the capillary, $\mathrm{R}$ its inner radius, and $\mu$ the viscosity of the liquid. In a typical experiment, $\mathrm{L}=15.5 \mathrm{~cm}, \mathrm{R}=10 \mu \mathrm{m}, \mu$ (methanol) $=5.84 \times 10^{-4} \mathrm{~Pa} \mathrm{~s}$, and $\Delta P=130$ Torr, yielding $\mathrm{Q}=7.5 \times 10^{-13} \mathrm{~m}^{3} / \mathrm{s}$. An electrospray of a TNT solution at a concentration of $0.1 \mathrm{mg} / \mathrm{mL}$ dispersed at that flow rate into a $\mathrm{CO}_{2}$ flow of $6 \mathrm{~L} / \mathrm{min}\left(4.16 \times 10^{-3}\right.$ $\mathrm{mol} / \mathrm{s}$ ) provides $80 \mathrm{ppt}$ in the vapor phase. To ensure that this liquid flow was rapidly evaporated and well mixed with the gas flow, the gas was heated, while the injected liquid was electrosprayed into small drops from the exit tip of the capillary. The temperature at the outer wall of the temperature-controlled Teflon line going from the vapor source to the charger was about $125^{\circ} \mathrm{C}$ for the API-365 experiments and about $150{ }^{\circ} \mathrm{C}$ for the API-5000 measurements. Note also that the latter has a heated entrance as a commercial feature. In the TOF measurements the Teflon line was surrounded by copper tubing kept at $200{ }^{\circ} \mathrm{C}$. To avoid confusions between the two electrosprays used in this system, they will be subsequently referred to as the "seeding" and the "charging" electrosprays, respectively. To ensure a comparable response between the open and closed electrospray ionization systems, we performed some preliminary open chamber tests on the API-365. We found that the signal is maximized at values similar to those obtained with the closed chamber, after optimizing the charging electrospray position and upon establishment of a driving voltage of $54 \mathrm{~V}$ between the charging ES chamber and the MS inlet. This optimized scheme was used with the API-5000.

Some of the analyte dissolved in the drops from the seeding ES may possibly have been initially in the form of ions. However, there is ample time for all ions to be neutralized in the chamber of the seeding electrospray and in downstream lines (all of Teflon or stainless steel,

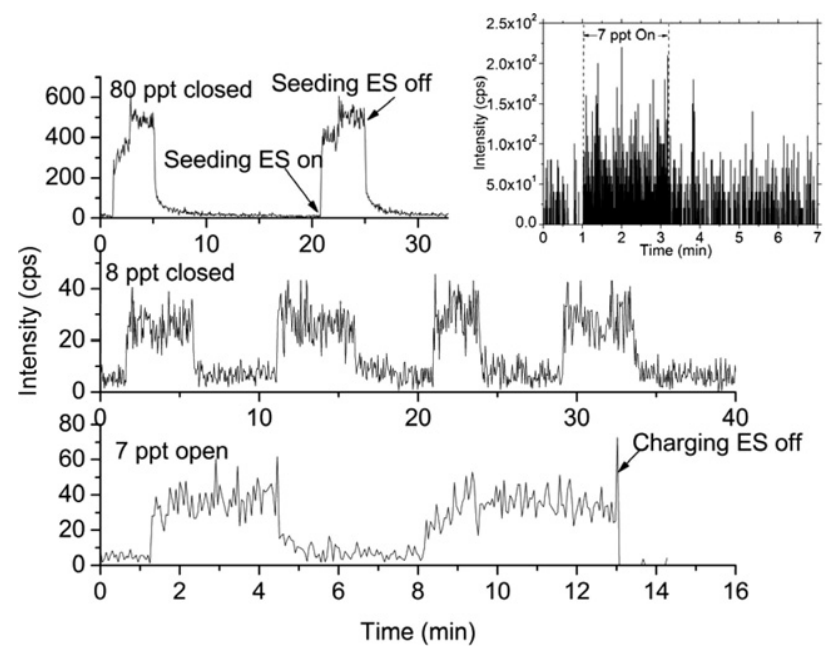

Figure 2. Signal for the $\mathrm{NO}_{2}^{-}$fragment of deprotonated $\mathrm{TNT}^{-}$at three concentrations of TNT vapor. API-365. The steps are created by turning on and off the injector, except for the abrupt fall to zero, marked with an arrow, resulting from turning off the charging ES. Note comparable responses for the enclosed source and the one open to the atmosphere. Dwell time $=3 \mathrm{~s}$. The inset corresponds to 7 ppt of TNT vapors, monitored through the $\mathrm{NO}_{2}{ }^{-}$fragment (46 Da), with a dwell time of $100 \mathrm{~ms}$.

and all surrounded by heating tape up to the ES charging chamber preceding the mass spectrometer inlet). We checked that this vapor injector produces no analyte ions by observing that the MS signal falls immediately to zero when turning off the charging ES while keeping the seeding ES on.

\section{Experiments with the API-365}

The mass spectra obtained while seeding TNT vapors, with $0.1 \% \mathrm{NH}_{3}$ in the charging $\mathrm{ES}$ run in negative mode, are dominated by deprotonated $\mathrm{TNT}^{-}$(226 Da). Upon injecting 80 ppt of TNT, one can clearly see a large increase in signal (to $\sim 130,000 \mathrm{cps}$ ) above the usual blank at $226 \mathrm{~m} / \mathrm{z}(\sim 12,700 \mathrm{cps}$, typical background for this quad). The background corresponds to an unidentified species different from TNT. As shown in Figure 2, the interfering background can be largely eliminated by fragmenting the deprotonated $\mathrm{TNT}^{-}$selected on the first quadrupole, and monitoring on the third quadrupole for the dominant product ion, $\mathrm{NO}_{2}{ }^{-}(46 \mathrm{Da})$. It is clear from these experiments that the limit of detection in MS/MS with a dwell time of $3 \mathrm{~s}$ is better than $7 \mathrm{ppt}$. The inset on the right of the top figure shows how this same concentration can only be barely guessed when the dwell time is reduced to $100 \mathrm{~ms}$. Another limiting feature also observed in the figure is the relatively long time required for the signal to return to zero after interrupting TNT injection. This memory effect was subsequently reduced by increasing the temperature in the flow lines. Figure 2 demonstrates also the effect of turning off the charging $\mathrm{ES}$ (at $\mathrm{t}=13 \mathrm{~min}$ ) while keeping on the injector of TNT. The instantaneous and complete elimination of the signal shows that the TNT 


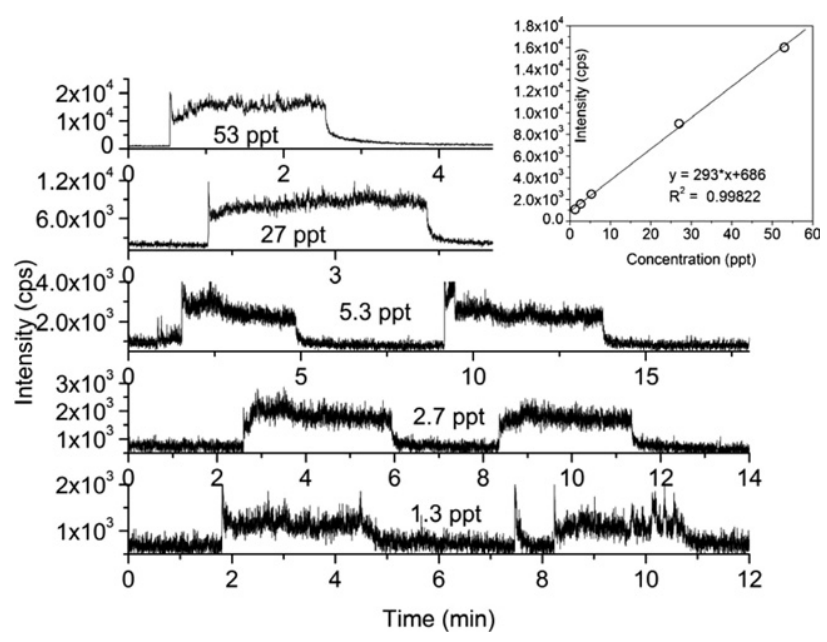

Figure 3. Response of the API-5000 to deprotonated TNT vapors monitored through its $\mathrm{NO}_{2}{ }^{-}$fragment (46 Da) at dwell time of 100 $\mathrm{ms}$. The inset shows the corresponding calibration curve.

injector delivers neutral vapor. Note finally the similar response for the open and closed ionization systems in the lower range of detection, though with a clear increase in noise level for the open system.

\section{Experiments with the API-5000}

This more modern instrument has a sampling orifice of $0.6 \mathrm{~mm}$ (versus $0.25 \mathrm{~mm}$ in the 365) and therefore ingests a flow rate some 6 times larger than the API-365. The ion transmission and counting efficiency are also much improved. Indeed, a transmission efficiency of $20 \%$ has been demonstrated for a nanospray source located close to the inlet orifice [32]. We do not know the transmission efficiency of the API-365, but it may be estimated to be of a few percent. So, a signal increase (due to a larger sample, more efficiently transmitted) roughly of the order of 100 can be expected in the API-5000, with an associated increase of about 10 in signal/noise. As already noted, another change in the experimental setup is that the charging chamber is not enclosed but open to the atmosphere of the laboratory. Also, its temperature was raised from $125^{\circ} \mathrm{C}$ up to $\sim 150^{\circ} \mathrm{C}$. The dwell time (length of time during which the ion current is monitored at a fixed $\mathrm{m} / \mathrm{z}$ to produce an individual datum in a mass spectrum or a TIC spectrum) for most of the experiments with this instrument was reduced to $0.1 \mathrm{~s}$. All the measurements were in MS/MS mode.

Figure 3 (right) shows the linearity of the response of the API-5000 in MS-MS to various concentrations of TNT vapor, revealing a detection limit of about $1 \mathrm{ppt}$, limited by the chemical noise background. The signal intensity is two orders of magnitude larger than in the API-365, but the noise level is also greatly increased (in part due to the much smaller dwell time, but also due to the larger sample flow, and possibly also to the use of a charger open to the laboratory atmosphere). The sig-

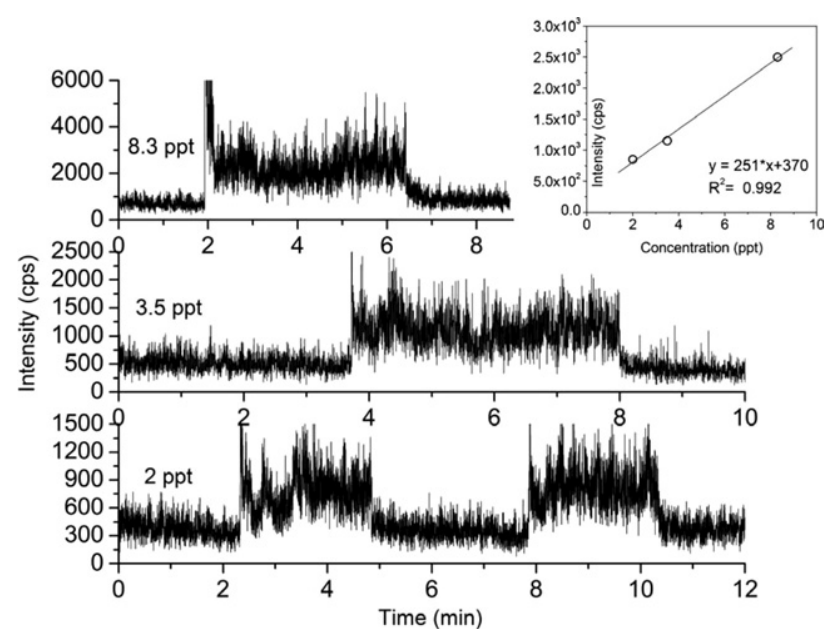

Figure 4. Response of the API-5000 to PETN, monitored through the product ion $\mathrm{NO}_{3}{ }^{-}$of the precursor ion PETN + acetate ${ }^{-}$. Dwell time $=0.1 \mathrm{~s}$. The inset shows the corresponding calibration curve.

nal/noise improvement with respect to the API-365 is at least a factor of 10 , as can be seen by comparing the datum for $5.3 \mathrm{ppt}$ in Figure 3 with the upper inset in Figure 2 (API-365 at $7 \mathrm{ppt}$ ), both taken with the same dwell time of $100 \mathrm{~ms}$. Note in Figure 3 that the decay in the signal after turning off the vapor feed is in this case faster than before, due to the temperature increase. The line is fully heated in the case of the API-5000, in contrast to the API-365 set up, where the closed chamber containing the charging electrospray was not heated.

We have similarly examined the response of this mass spectrometer to PETN vapors. In this case the charging ES uses acetic acid, the primary ion is PETN complexed with acetate, and its dominant product ion, $\mathrm{NO}_{3}{ }^{-}(62 \mathrm{Da})$, is monitored. Other dominant species in the fragmentation spectrum are $\mathrm{NO}_{2}^{-}(46 \mathrm{Da})$ and acetate $^{-}(59 \mathrm{Da})$. The results shown in Figure 4 indicate a lower detection limit comparable to that for TNT. Figure 5 shows the reduction in noise obtained by increasing the dwell time to $1 \mathrm{~s}$, demonstrating a lower detection limit approaching $0.2 \mathrm{ppt}$. This unprecedented low value is almost 100 times below the roomtemperature vapor pressure of PETN [33].

\section{Experiments with the TOF Instrument}

The TOF experiments were performed in SEADM's laboratory, with a charger and vapor generator almost identical to those used with the API-365. The interfering peaks appearing at masses slightly different from that of deprotonated TNT (226.009 Da) are now cleanly resolved in the TOF spectrum (Figure 6, right), even in single MS mode. High-resolution hence translates into a very low background noise, as can be seen in Figure 6 (left) obtained at varying concentrations of TNT in the vapor phase. Using a sampling period of $1 \mathrm{~s}$ (accumulation time during which many TOF spectra are ac- 


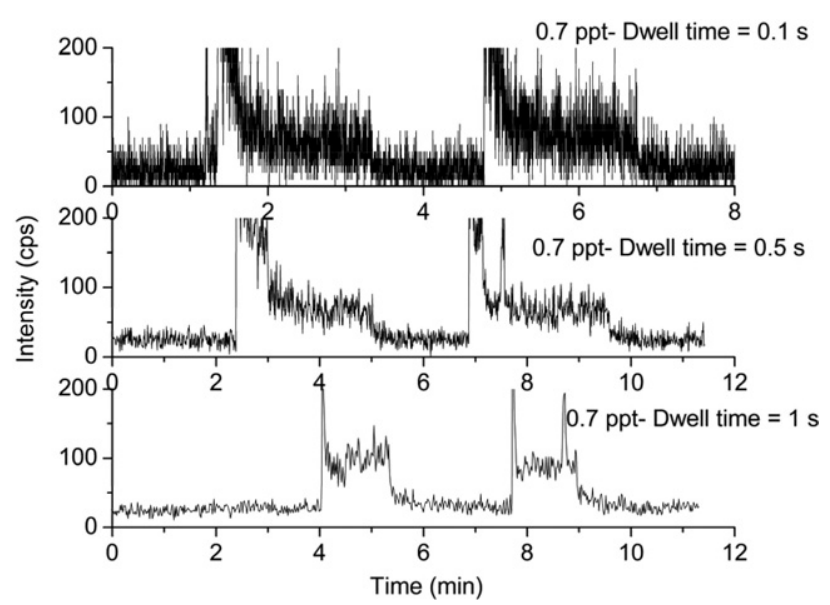

Figure 5. Effect of dwell time $\Delta t$ on signal/noise with PETN vapors. At $\Delta \mathrm{t}=1 \mathrm{~s}$, the lower detection limit approaches $0.2 \mathrm{ppt}$. Other experimental conditions as in Figure 4.

quired and averaged), the background signal is stable enough to allow detection of the lowest TNT concentration shown of $1.1 \mathrm{ppt}$.

\section{Discussion}

Our results have demonstrated detection limits below 1 ppt for two of the three MS systems tested. We are not aware of any other instance where such levels have been achieved from unconcentrated vapor samples. Similar results have been previously quoted in the literature based on indirect evidence. In the most systematic study available as a journal article [6], from which Steinfeld and Wormhoudt [7] infer an ability to detect $10 \mathrm{ppt}$ of explosive, the samples of TNT or RDX were placed in condensed phase near the inlet to the mass spectrometer. However, even though the roomtemperature vapor pressure of RDX approaches $10 \mathrm{ppt}$ and that of TNT greatly exceeds it, the sample had to be heated to be detected. In fact, no lowest detection limit in the form of a gas-phase concentration was given in [6]. What was reported was the minimum detectable mass of sample (an impressive $10^{-13} \mathrm{~g}$ ), which is what was measured, and what is relevant for instruments based on particle (or condensed phase) analysis. What we are exploring here, however, is the viability of measuring a vapor preexisting in the gas phase, and in this respect clearly modern commercial API-MS instruments coupled to a suitable vapor charger are better than all other known MS alternatives. These encouraging results, however, must be put in perspective of (1) the concentration thresholds that would be desirable for explosive detection in the field based only on their vapor concentration in the atmosphere, and (2) the sensitivity of insects. Note first that the room-temperature vapor pressure of an explosive such as HMX is of the order of $2 \times 10^{-4} \mathrm{ppt}$, and that its detection in open air would require probably detection thresholds below $10^{-6} \mathrm{ppt}$. We are therefore many orders of magnitude poorer than what is needed. Note also that an instrument sampling $1 \mathrm{~L} / \mathrm{min}$ of atmospheric air would be taking $0.42 \times 10^{8}$ molecules in $100 \mathrm{~ms}$ of a vapor present at $1 \mathrm{ppt}$, which is similar to our present record performance. In contrast, certain insects are said to be capable of sensing a single pheromone molecule lucky enough to come in contact with the tiny surface of their detectors.

Table 2 collects our TNT vapor detection data for the three mass spectrometers tested in the different modes in which they have been used. The first two columns of the table, sensitivity and detection probability, as well as the fourth column, mean value of the background, are average values for all the experiments performed on the system. To facilitate the quantitative interpretation of these measurements, we introduce the following definitions:
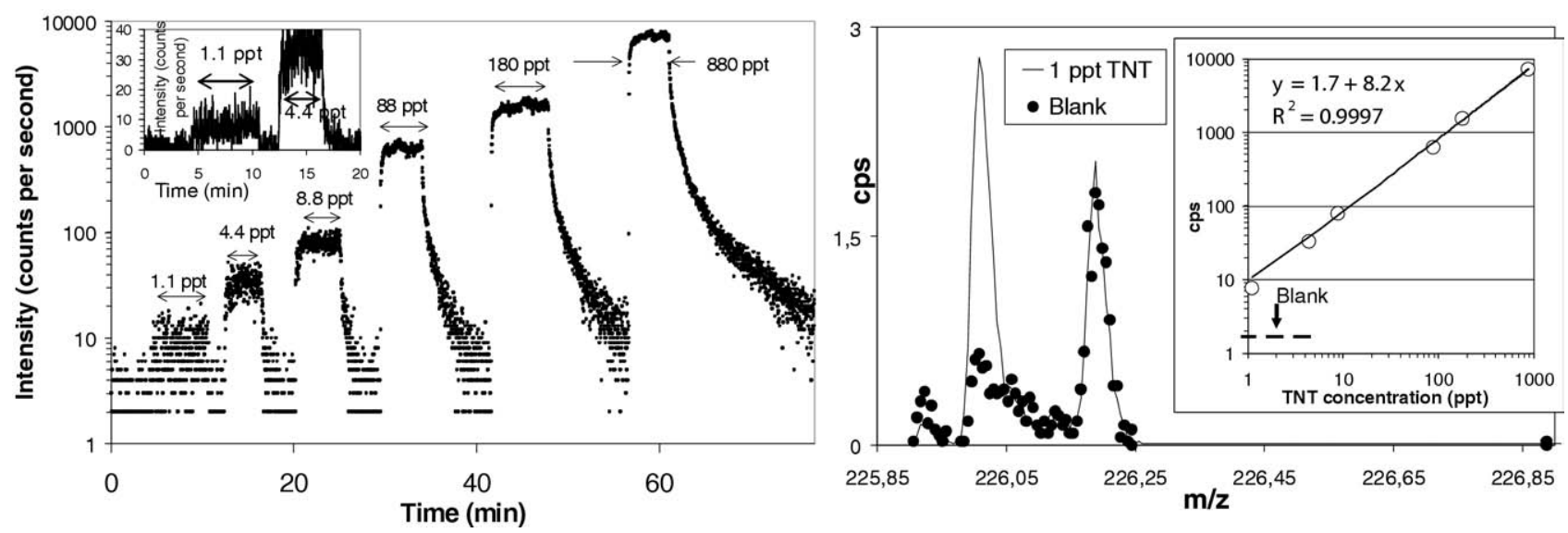

Figure 6. Q-Star experiments with TNT in MS ${ }^{1}$ mode; $\Delta \mathrm{t}=1 \mathrm{~s}$. Left, total ion current for $m / z$ between 226.000 and 226.015 Da at different vapor concentrations. The inset shows in greater detail the steps at 1.1 and $4.4 \mathrm{ppt}$. Right, TOF spectrum with $1.1 \mathrm{ppt}$ of TNT (averaged for $2 \mathrm{~min}$ ), neatly resolving the peak of deprotonated TNT (continuous line) from the background (data points). The inset on the right shows the calibration line for signal versus vapor concentration. 
Table 2. Compilation of TNT vapor detection information for the various mass spectrometers tested, with key quantities defined in the text

\begin{tabular}{|c|c|c|c|c|c|c|c|c|}
\hline \multirow[b]{2}{*}{ MS type/mode } & \multirow[b]{2}{*}{$\begin{array}{l}\text { Sensitivity } \\
\text { S (cps/ } \\
\text { ppt) }\end{array}$} & \multirow[b]{2}{*}{$\begin{array}{c}\text { Detection } \\
\text { probability } \\
\mathrm{p}_{\mathrm{t}} \\
\end{array}$} & \multirow[b]{2}{*}{$\begin{array}{l}\Delta \mathrm{t} \\
(\mathrm{s})\end{array}$} & \multicolumn{2}{|c|}{ Background } & \multirow[b]{2}{*}{$\begin{array}{l}\text { Detection } \\
\text { threshold } \\
\text { LDL (ppt) } \\
\end{array}$} & \multirow[b]{2}{*}{$\begin{array}{l}\text { Minimum sample } \\
\text { rate (sample } \\
\text { molecules/s) }\end{array}$} & \multirow[b]{2}{*}{$\begin{array}{c}\text { Minimum sample } \\
\text { (molecules) }\end{array}$} \\
\hline & & & & $\begin{array}{l}<\mathrm{B}> \\
\text { (cps) }\end{array}$ & $\begin{array}{l}\text { Noise } B^{\prime}{ }_{99.5} \\
\text { (cps) }\end{array}$ & & & \\
\hline 365 quad/MS ${ }^{1}$ & 1500 & $7.1 \times 10^{-6}$ & 0.08 & 12000 & 4000 & 2.7 & $5.6 \times 10^{8}$ & $0.4 \times 10^{8}$ \\
\hline 365 quad/MS ${ }^{2}$ & 6.1 & $2.9 \times 10^{-8}$ & 3 & 5.1 & 8.9 & 1.5 & $3.1 \times 10^{8}$ & $9.2 \times 10^{8}$ \\
\hline 5000 quad/MS ${ }^{2}$ & 290 & $2.4 \times 10^{-7}$ & 0.1 & 690 & 330 & 1.1 & $1.3 \times 10^{9}$ & $1.3 \times 10^{8}$ \\
\hline 5000 quad/MS ${ }^{2}$ & & & 0.5 & & 170 & 0.6 & $0.7 \times 10^{9}$ & $3.5 \times 10^{8}$ \\
\hline 5000 quad/MS ${ }^{2}$ & & & 1 & & 130 & 0.4 & $0.5 \times 10^{9}$ & $5.4 \times 10^{8}$ \\
\hline 5000 quad/MS ${ }^{2 *}$ & & & 3 & & 80 & 0.3 & $0.3 \times 10^{9}$ & $10.1 \times 10^{8}$ \\
\hline $\mathrm{TOF} / \mathrm{MS}^{1}$ & 8.2 & $3.9 \times 10^{-8}$ & 1 & 1.7 & 5.3 & 0.6 & $1.4 \times 10^{8}$ & $1.4 \times 10^{8}$ \\
\hline
\end{tabular}

*With a $\Delta \mathrm{t}^{1 / 2}$ extrapolation of the experimental noise data to $\Delta \mathrm{t}=3 \mathrm{~s}$.

$\mathrm{C}(\mathrm{ppt})=$ ambient concentration of gas-phase explosive $=n / n_{0}$. It is a dimensionless number, where $n$ (molecules $/ \mathrm{cm}^{3}$ ) is the number concentration of explosive vapor in the sampled gas, and $\mathrm{n}_{\mathrm{o}}=\mathrm{p}_{\mathrm{o}} / \mathrm{kT}_{\mathrm{o}}(\sim 2.5$ $10^{19}$ molecules $\left./ \mathrm{cm}^{3}\right)$ is the number concentration of carrier gas molecules at ambient conditions $\left(\mathrm{p}_{\mathrm{o}}=1 \mathrm{~atm}\right.$; $\left.\mathrm{T}_{\mathrm{o}}=293 \mathrm{~K}\right)$

$\mathrm{s}(\mathrm{cps})=$ ion count rate, or ion current received by the mass spectrometer

$\Delta \mathrm{t}(\mathrm{s})=\mathrm{d}$ well time, or time over which the signal is collected. In the quadrupole this time is used entirely to collect the ions of interest. In the TOF measurements $\Delta t$ means the time over which MS spectra are accumulated, only part of which is devoted to collect the ion of interest, leading to a certain inefficiency or duty cycle.

$\mathrm{S}(\mathrm{cps} / \mathrm{ppt})=$ Sensitivity $=\mathrm{s} / \mathrm{C}$, determined from the slope of the calibration curve (signal increase $\Delta \mathrm{s}$ upon injection of a certain $\Delta C$ )

$\mathrm{p}_{\mathrm{t}}$ (dimensionless) $=$ detection probability $=$ ion count rate/(neutral vapor sample rate $)=\mathrm{s} /\left(\mathrm{nQ}_{\mathrm{MS}}\right)=$ $\left(\mathrm{s} / \mathrm{n}_{\mathrm{o}}\right) /\left(\mathrm{Q}_{\mathrm{MS}} \mathrm{n} / \mathrm{n}_{\mathrm{o}}\right)=\mathrm{S} /\left(\mathrm{Q}_{\mathrm{MS}} \mathrm{n}_{\mathrm{o}}\right)$, where $\mathrm{Q}_{\mathrm{MS}}(\mathrm{L} / \mathrm{min})$ is the flow rate of gas sampled into the mass spectrometer through its inlet orifice, collected in Table 3. $p_{t}=p_{i} p_{t d}$ can be separated into the probability of ionization $p_{i}$, and the probability of transmission and detection

$\mathrm{p}_{\mathrm{i}}=$ ionization probability $=$ (analyte ions in sample flow rate)/(neutral analyte molecules in sampled flow rate)

$\mathrm{p}_{\mathrm{td}}=$ efficiency of transmission and detection $=$ (ions counted in the detector)/(ions entering the MS pinhole)

$\mathrm{B}(\mathrm{cps})=$ ion signal detected at the analyte mass in the absence of analyte. We distinguish between its steady mean value $<B>$ and its fluctuations or noise $\mathrm{B}^{\prime}=\mathrm{B}-<\mathrm{B}>$.

$\mathrm{B}^{\prime}{ }_{99.5}$ is the value of the background noise such that $99.5 \%$ of the measurements with no sample yield a signal below $<\mathrm{B}>+\mathrm{B}^{\prime}{ }_{99.5}$

Table 3. Flow rates of ambient gas sampled into the three mass spectrometers

\begin{tabular}{cccc}
\hline MS & API-365 & API-5000 & Q-Star \\
\hline \hline $\mathrm{Q}_{\mathrm{MS}}(\mathrm{L} / \mathrm{min})$ & 0.5 & 2.9 & 0.5 \\
\hline
\end{tabular}

LDL $(\mathrm{ppt})=$ lowest detection limit or detection threshold $=\mathrm{B}^{\prime}{ }_{99.5} / \mathrm{S}$. In view of the definition of $\mathrm{B}$, it corresponds to the smallest analyte concentration yielding fewer than $0.5 \%$ false alarms.

Minimum sample rate (sample molecules per second) $=$ the sampling rate at the detection threshold $=$ $\mathrm{B}^{\prime}{ }_{99.5} / \mathrm{p}_{\mathrm{t}}$

Minimum sample $($ molecules $)=\Delta t \cdot($ minimum sample rate) (molecules)

The key quantity LDL may be written as

$\mathrm{LDL}=\mathrm{B}^{\prime}{ }_{99.5} / \mathrm{S}=\mathrm{B}^{\prime}{ }_{99.5} /\left(\mathrm{p}_{\mathrm{t}} \mathrm{Q}_{\mathrm{MS}} \mathrm{n}_{\mathrm{o}}\right)$,

which quantifies the obvious interest of reducing noise, increasing sample flow rate, and increasing the detection probability. In view of the complexities surrounding the noise level $\mathrm{B}^{\prime}{ }_{99.5}$, we will leave it aside for the moment, and deal first with the equally important and more readily quantifiable probability $p_{t} \cdot p_{t}$ is not affected by background or noise, and is just the ratio of the signal measured over the signal one could obtain if all the neutral molecules sampled into the MS were detected. In the absence of noise, the least one would need for detection is one count during the sampling time, which sets the lower limit for an effective statistical noise $\mathrm{B}^{\prime \prime}{ }_{99.5}>1 / \Delta \mathrm{t}$

$\mathrm{LDL}>1 /(\mathrm{S} \Delta \mathrm{t})=1 /\left(\mathrm{p}_{\mathrm{t}} \Delta \mathrm{t} \mathrm{Q}_{\mathrm{MS}} \mathrm{n}_{\mathrm{o}}\right)$.

This ideal is by no means unreachable, nor irrelevant to our own data. For instance, in our TOF experiments $\mathrm{B}^{\prime}{ }_{99.5}$ is only $5.3 \mathrm{cps}$ for $\Delta \mathrm{t}=1 \mathrm{~s}$, so we are off by just a factor of 5.3 from the noiseless limit. In reality, what limits ultimately our ability to detect TNT in the TOF instrument is not the noise but the finite sampling time used, as evident in the long time average shown in Figure 6 right. The background at the mass of TNT is about $0.5 \mathrm{ppt}$, and the almost exact matching of masses between signal and background suggests strongly that this background is in fact due to TNT contamination of our insufficiently heated system. If $p_{t}$ were unity, in this ideal noiseless limit, LDL would be as small as $1 /\left(\Delta \mathrm{tQ}_{\mathrm{MS}} \mathrm{n}_{\mathrm{o}}\right)=4.810^{-9} \mathrm{ppt}(\Delta \mathrm{t}=1 \mathrm{~s})$. But $\mathrm{p}_{\mathrm{t}}$ is in fact tiny, $3.910^{-8}$ for the data of Figure 6, and this factor alone already brings LDL up to $0.13 \mathrm{ppt}$, even in a noiseless environment $(\Delta t=1 \mathrm{~s})$. A most striking characteristic of our data is the exceedingly low detection 
probabilities found, at best $7 \times 10^{-6}$ for a quadrupole in $\mathrm{MS}^{1}$ mode, and over one and two orders of magnitude worse for a quadrupole in $\mathrm{MS}^{2}$ mode and a TOF-MS, respectively.

The vast inefficiency quantified in the detection probability column can be separated into two broad factors. One is the ionization efficiency, $p_{i}$, defined as the ratio of the flux of ions entering the inlet pinhole of the MS divided by the flux of neutral molecules that would be carried by the sample flow rate of the MS. This is strictly a property of the charger, and we are not aware of any prior measurements of it for any vapor charger. The other key quantity, $\mathrm{p}_{\mathrm{td}}$ is the efficiency of transmission and detection of an ion having already been sampled into the mass spectrometer. This later quantity has been previously studied for triple quadrupoles, though in combination with the ionization efficiency of a nanoelectrospray source (see [34] and its bibliography). However, these nanospray experiments often show saturation in the efficiency with the liquid flow rate at the source, which can be interpreted as due to $100 \%$ charging efficiency. Nanospray sources also offer the possibility to pass almost all the source current through the inlet orifice to the mass spectrometer, so that it is reasonable to identify the quantity $p_{t d}$ with the maximum overall efficiency observed. This implies $p_{t d}$ values between a few percent up to $12 \%$. The data of El-Faramawy et al. [34] were for SCIEX's API-3000, which is intermediate between the API-5000 and the API-365. A more recent study reports an even larger transmission of $20 \%$ for the API-5000 [32]. This information enables conversion of the largest detection probability within our data $\left(7.1 \times 10^{-6}\right.$ for the API-365 in single MS) into a charging probability by assuming a $10 \%$ MS transmission and counting efficiency. This leads to an ionization probability $\mathrm{p}_{\mathrm{i}} \sim 10^{-4}$. The current efficiency of ion transmission inside the mass spectrometer, estimated at about $10 \%$, represents a relatively irrelevant barrier, and is rapidly approaching unity in modern quadrupole instruments in $\mathrm{MS}^{1}$ mode [32]. Future improvements in API-MS systems used for volatiles will therefore need to work hard on improved charging efficiency.

The minimum sample column of Table 2 transmits a message of even greater inefficiency than $p_{t}$, since these data take now into account the fact that there is a noise level greater than one count in the measurement period, $\mathrm{B}^{\prime}{ }_{99.5} \Delta \mathrm{t}>1$. Indeed, the minimum sample can be expressed as $\mathrm{B}^{\prime}{ }_{99.5} \Delta \mathrm{t} / \mathrm{p}_{\mathrm{t}}$, which is larger than $1 / \mathrm{p}_{\mathrm{t}}$. The net result is that typically one hundred million sample molecules are required for detection with $99.5 \%$ confidence. Of this $10^{8}$ global inefficiency, we have already identified the charger as responsible for a $10^{4}$ factor, with another order of magnitude in quadrupoles due to imperfect ion transmission from the mass spectrometer inlet to the detector. The remaining $10^{3}$ inefficiency factor can then, in the case of quadrupoles, be generically attributed to noise. Future improvements in API-MS quadrupoles used for volatiles will therefore benefit almost as much from background reduction as from improved charging efficiency. The case of the TOF is quite different due to the additional duty cycle inefficiency, which is approximately compensated by the greatly reduced noise. For this instrument type it is apparently more advantageous to increase charging efficiency than to reduce background.

These results are of course peculiar to our conditions and not directly applicable to other chargers and detectors. But they provide some lower bounds to the performance presently achievable. Examples of the limitations of our measurements are clear in the relatively high loss of signal resulting when passing from single MS to $\mathrm{MS}^{2}$ (a 300-fold signal loss), which can surely be reduced, not only in this instrument, but particularly in more modern systems. For instance, we have recently obtained long-term access to an API-5000, and observed a signal loss by a factor of 6 to 7 in similar TNT experiments when going from $\mathrm{MS}^{1}$ to $\mathrm{MS}^{2}$. After tuning the instrument for gas-phase TNT detection, we observe a sensitivity eight times higher than the value shown in Table 2 (290 cps/ppt), which provides a more reasonable comparison between the sampling count probabilities for the API-365 and the API-5000.

Another variable with a strong influence on the LDL is the sampling time $\Delta \mathrm{t}$. While LDL $\sim 1.5 \mathrm{ppt}$ for the API-365 in $\mathrm{MS}^{2}$ mode with $\Delta \mathrm{t}=3$ s (inferred from the experiments in Figure 2), Figure 3 (right), corresponding to $\Delta \mathrm{t}=0.1 \mathrm{~s}$, is closer to LDL $\sim 15 \mathrm{ppt}$. The only systematic study we have made on the effect of dwell time was performed on the API-5000. The corresponding detection thresholds are shown in Table 2, including a $\mathrm{B}_{99.5}^{\prime} \sim \Delta \mathrm{t}^{-1 / 2}$ extrapolation to $3 \mathrm{~s}$ to enable comparison with the API-365 data. The API-5000 has a lower detection threshold some five times smaller than the API-365.

\section{Conclusions}

A study of the ability of several API-MS systems to detect the vapors of low volatility explosives ionized by SESI has been carried out. We find that (1) as previously noted by Fenn and colleagues, this charging method is quite effective in forming ions not only from neutral vapors, but also from small aerosol particles. (2) TNT and PETN vapors can be detected at concentrations as small as 1 ppt with sampling times of $0.1 \mathrm{~s}$. At sampling times of $1 \mathrm{~s}$ one can detect PETN at a concentration almost $1 / 100$ of its roomtemperature vapor pressure. (3) Nonetheless, the inefficiency of the process is still vast, with $10^{8}$ sample molecules being typically required for detection. (4) This inefficiency can be roughly divided into a $10^{-4}$ charging probability, a $10 \%$ ion transmission and counting probability in the MS, and a $10^{-3}$ interference associated to background noise. 


\section{Acknowledgments}

The authors gratefully acknowledge Mr. Francisco Estevez, Mr. David Moro, and Mrs. Erica Mesonero for their participation in the early and final phases of this study. They also thank Dr. B. Thomson and Mr. H. Javaheri for hosting the experiments with the API-5000, and B. Thomson for his many suggestions on the manuscript. This study was financed primarily by SEADM. PML expresses his gratitude to Yale University for hosting his postdoctoral visit.

\section{References}

1. Fialkov, A. B.; Steiner, U.; Lehotay, S. J.; Amirav, A. Sensitivity and Noise in GC-MS: Achieving Low Limits of Detection for Difficult Analytes. Int. J. Mass Spectrom. 2007, 260(1), 31-48.

2. Lindinger, W.; Hansel, A.; Jordan, A. On-Line Monitoring of Volatile Organic Compounds at pptv Levels by Means of Proton-TransferReaction Mass-Spectrometry (PTR-MS): Medical Applications, Food Control, and Environmental Research. Int. J. Mass Spectrom. Ion Processes 1998, 173(3), 191-241.

3. Smith, D.; Španěl, P. Selected Ion Flow Tube Mass Spectrometry (SIFT-MS) for On-Line Trace Gas Analysis. Mass Spectrom. Rev. 2005, 24(5), 661-700.

4. McMurry, P. H.; Fink, M.; Sakurai, H. Stolzenburg, M. R.; Mauldin, R. L.; Smith, J.; Eisele, F.; Moore, K.; Sjostedt, S.; Tanner, D.; Huey, L. G.; Nowak, J. B.; Edgerton, E.; Voisin, D. A Criterion for New Particle Formation in the Sulfur-Rich Atlanta Atmosphere. J. Geophys. Res. D: Atmospheres 2005, 110(22)D22S02, 1-10.

5. Asano, K. G.; Goeringer, D. E.; McLuckey, S. A. Parallel Monitoring for Multiple Targeted Compounds by Ion Trap Mass Spectrometry. Anal. Chem. 1995, 67(17), 2739-2742

6. McLuckey, S. A.; Goeringer, D. E.; Asano, K. G.; Vaidyanathan, G.; Stephenson, J. L. Jr. High Explosives Vapor Detection by Glow Discharge-Ion Trap Mass Spectrometry. Rapid Commun. Mass Spectrom. 1996, 10(3), 287-298.

7. Steinfeld, J. A.; Wormhoudt, J. Explosives Detection: A Challenge for Physical Chemistry. Annu. Rev. Phys. Chem. 1998, 49, 203-232.

8. Lane, D. A.; Thomson, B. A. Monitoring a Chlorine Spill from a Train Derailment. J. Air Pollution Control Assoc. 1981, 31(2), 122-127.

9. Davidson, W. R.; Thomson, B. A.; Akery, A. K.; Sleeman, R. Proceedings of the First International Symposium on Explosive Detection Technology; Atlantic City, NJ, November 13-15, 1991; pp 653-662.

10. Davidson, W. R.; Stott, W. R.; Akery, A.K.; Sleeman, R. Proceedings of the First International Symposium on Explosive Detection Technology; Atlantic City, NJ, November 13-15, 1991; pp 663-671.

11. Sleeman R.; Bennett, G.; Davidson, W. R.; Fisher, W. Proceedings of the International Symposium on Contraband and Cargo Inspection Technologies; Washington D.C., October 28-30, 1992; pp 57-63.

12. Davidson, W. R.; Stott, W. R.; Sleeman, R.; Akery, A. K. Conference on Substance Detection Systems, 1993, Innsbruck, Austria. Proc. SPIE 1994, 2092, 108.

13. Stott, W. R.; Davidson, W. R.; Sleeman, R. Proc. SPIE 1994, 2092, 53.

14. Bennett G.; Sleeman, R.; Davidson, W. R.; Stott, W. R. Proc. SPIE 1994, $2276,363$.
15. Davidson W. R.; Stott, W. R. Proceedings of the 50th ASMS Conference on Mass Spectrometry and Allied Topics: Orlando FL, June, 2002. TPK 300.

16. Fenn, J. B.; Mann, M.; Meng, C. K.; Wong, S. F.; Whitehouse, C. Electrospray Ionization for Mass Spectrometry of Large Biomolecules. Science 1989, 246, 64-71.

17. Yinon, J.; McClellan, J. E.; Yost, R. A. Electrospray Ionization Tandem Mass Spectrometry Collision-Induced Dissociation Study of Explosives in an Ion Trap Mass Spectrometer. Rapid Commun. Mass Spectrom. 1997, 11, 1961-1970.

18. Evans, C. S.; Sleeman, R.; Luke, J.; Keely, B. J. A Rapid and Efficient Mass Spectrometric Method for the Analysis of Explosives. Rapid Commun. Mass Spectrom. 2002, 16, 1883-1891.

19. Venter, A; Ifa, D. R.; Cooks, R. G.; Poehlein, S. K.; Chin A.; Ellison, D. A Desorption Electrospray Ionization Mass Spectrometry Study of Aging Products of Diphenylamine Stabilizer in Double-Base Propellants. Propell. Expl. Pyrotech. 2006, 31(6), 472-476.

20. Cotte-Rodriguez, I.; Chen, H.; Cooks, R. G. Rapid Trace Detection of Triacetone Triperoxide (TATP) by Complexation Reactions During Desorption Electrospray Ionization. Chem. Commun. 2006, 9, 953-955.

21. Cody, R. B.; Laramee, J. A.; Durst, H. D. Versatile New Ion Source for the Analysis of Materials in Open Air Under Ambient Conditions. Anal. Chem. 2005, 77(8), 2297-2302.

22. Whitehouse, C. M.; Levin, F.; Meng, C. K.; Fenn, J. B. Proceedings of the 34th ASMS Conference on Mass Spectrometry and Allied Topics; Cincinnati, OH, June 8-13, 1986; p 507.

23. Fuerstenau, S.; Kiselev, P.; Fenn, J. B. Proceedings of the 47th ASMS Conference on Mass Spectrometry Allied Topics; Dallas, TX, June, 1999; ThOE 3:00.

24. Wu, C.; Siems, W. F.; Hill, H. Jr. Secondary Electrospray Ionization Ion Mobility Spectrometry/Mass Spectrometry of Illicit Drugs. Anal. Chem. 2000, 72, 396-403.

25. Tam, M.; Hill, H. Jr. Secondary Electrospray Ionization-Ion Mobility Spectrometry for Explosive Vapor Detection. Anal. Chem. 2004, 76(10), 2741-2747.

26. Takáts, Z.; Wiseman, J. M.; Gologan, B.; Cooks, R. G. Mass Spectrometry Sampling Under Ambient Conditions with Desorption Electrospray Ionization. Science 2004, 306, 471-473.

27. Chen, H.; Venter, A.; Cooks, R. G. Extractive Electrospray Ionization for Direct Analysis of Undiluted Urine, Milk and Other Complex Mixtures without Sample Preparation. Chem. Commun. 2006, 2042-2044.

28. Chen, H.; Wortmann, A.; Zhang, W.; Zenobi, R. Rapid In Vivo Fingerprinting of Nonvolatile Compounds in Breath. Angew. Chem. Int. Ed. 2007, 46, 580-583.

29. Martínez-Lozano, P.; Fernández. de la Mora, J. Electrospray Ionization of Volatiles in Breath. Int. J. Mass Spectrom. 2007, 265, 68-72.

30. Chen, H.; Sun, Y.; Wortmann, A.; Gu, H. ; Zenobi, R. Differentiation of Maturity and Quality of Fruit Using Noninvasive Extractive Electrospray Ionization Quadrupole Time-of-Flight Mass Spectrometry. Anal. Chem. 2007, 79, 1447-1455.

31. Chingin, K.; Gamez, G.; Chen, H.; Zhu, L.; Zenobi, R. Rapid Classification of Perfumes by Extractive Electrospray Ionization Mass Spectrometry (EESI-MS). Rapid Commun. Mass Spectrom. 2008, 22, 2009-2014.

32. Javaheri, H.; Thomson, B.A. Proceedings of the 57th ASMS Conference on Mass Spectrometry and Allied Topics; Indianapolis, IN, June, 2007.

33. Dionne, B. C.; Rounbehler, D. P.; Achter, E. K.; Hobbs, J. R.; Fine, D. H Vapor Pressure of Explosives. J. Energ. Mat. 1986, 4(1), 447-472.

34. El-Faramawy, A.; Siu, K. W. M.; Thomson, B. A. Efficiency of NanoElectrospray Ionization. J. Am. Soc. Mass Spectrom. 2005, 16(10), 17021707. 